\title{
Intravitreal triamcinolone acetonide: Pattern of secondary intraocular pressure rise and possible risk factors
}

\author{
Ziad F Bashshur' \\ Abdallah M Terro' \\ Christelle P El Haibi' \\ Akaber M Halawi ${ }^{1}$ \\ Alexandre Schakal ${ }^{2}$ \\ Baha' N Noureddin' \\ 'The Department of Ophthalmology, \\ American University of Beirut, \\ Lebanon; ${ }^{2}$ The Department of \\ Ophthalmology, Hotel Dieu de France \\ (St. Joseph University), Lebanon
}

Correspondence: Baha' N Noureddin Chairman, Department of Ophthalmology, American University of Beirut, Riad El Solh II-0236, Beirut, Lebanon

Tel +9611350000

Fax +96| I 370837

Email bndean@aub.edu.lb
Purpose: To determine the pattern of increase in intraocular pressure (IOP) following intravitreal triamcinolone acetonide (IVTA) and identify possible risk factors associated with this rise in IOP.

Methods: We carried out a retrospective review of records for 185 patients (226 eyes) who received $4 \mathrm{mg}$ of IVTA at the American University of Beirut Medical Center and Hotel Dieu de France eye clinics between 2003 and 2005

Results: Mean follow-up was 8.17 months (range 6 to 24 months). The mean number of IVTA injections per eye was $1.31 \pm 0.69$. The mean IOP increased after the first IVTA injection from $15.04 \pm 3.18 \mathrm{mmHg}$ at baseline to a mean maximum of $17.20 \pm 5.75 \mathrm{mmHg}$ ( $\mathrm{p}<0.0001$, paired t-test) at month 3 of follow-up with a return to mean baseline IOP $(15.49 \pm 4.79 \mathrm{mmHg})$ at month 12 . Fifty nine of 226 eyes showed IOP higher than $21 \mathrm{mmHg}$ during follow-up. Nine eyes started to have IOP greater than $21 \mathrm{mmHg}, 6$ to 12 months after a single injection. Intraocular pressure lowering medications were started when IOP exceeded $25 \mathrm{mmHg}$ in 15 of the 226 eyes studied. No risk factors have been found to predict this IOP rise

Conclusions: IOP elevation can occur in a significant number of eyes receiving $4 \mathrm{mg}$ of IVTA. This phenomenon seems to be transient and a small number of eyes required treatment during this period. Eyes that received IVTA need to be monitored for IOP changes especially during the first 3 months, but the IOP may still rise 6 months and even 12 months after a single injection. This study did not show any risk factor that may predict this IOP rise

Keywords: intravitreal triamcinolone acetonide, intraocular pressure elevation, diabetic macular edema, choroidal neovascular membrane due to age-related macular degeneration, central retinal vein occlusion, Branch retinal vein occlusion, Uveitis

\section{Introduction}

Intravitreal corticosteroids play an effective role in reducing inflammatory intraocular conditions (Wingate and Beaumont 1999; Antcliff et al 2001; Jonas et al 2001a, 2001b, 2003b; Degenring and Jonas 2003; Degenring et al 2003; Gillies et al 2003; Spaide et al 2003; Massin et al 2004; Smithen et al 2004). This anti-inflammatory action is exerted by inhibiting the formation of major inflammatory mediators such as leukotrienes and prostaglandins (Edelman et al 2005; Tamura et al 2005). Moreover, corticosteroids also decrease cellular permeability by inhibiting the expression of several endothelial growth factors and intracellular adhesion molecules (Edelman et al 2005; Tamura et al 2005).

Among the several routes of ocular corticosteroid delivery, the intravitreal route was found to insure adequate drug penetration and bioavailability (Jonas 2002a, 2002b, 2004; Beer et al 2003). Moreover, the crystalline form of corticosteroids ensures a longer period of intraocular availability.

Intravitreal injection of triamcinolone acetonide (IVTA) has been used successfully in the treatment of macular edema caused by diabetes mellitus (Jonas et al 2001b; 
Massin et al 2004), pseudophakia (Jonas et al 2003b), central retinal vein occlusion (Degenring et al 2003), and uveitis (Antcliff et al 2001; Degenring and Jonas 2003). It was also effective against various vasoproliferative conditions such as proliferative diabetic retinopathy (Jonas et al 2001a), age related macular degeneration (Gillies et al 2003), and iris neovascularization (Jonas et al 2001b).

Several side effects are well known and reported in IVTA treatment, such as cataract formation and post-injection endophthalmitis (infectious or sterile) (Benz et al 2003; Jonas et al 2003a; Ozkiris and Erkilic 2005; Jonas et al 2005). The most commonly reported side effect of IVTA is a transient rise in intraocular pressure (IOP) (Wingate and Beaumont 1999; Bakri and Beer 2003; Jonas et al 2003c; Massin et al 2004). Ozkiris and Erkilic (2005) reported a rise in IOP above 21 $\mathrm{mmHg}$ in $21 \%$ of the eyes receiving $8 \mathrm{mg}$ of IVTA, while Jonas and colleagues (2005) reported a similar IOP rise in $41 \%$ of patients receiving a $20 \mathrm{mg}$ dose. This IOP rise was found to be transient whereby the mean IOP at 9 months after IVTA was not statistically different from mean pre-injection values. Bakri and Beer (2003) reported a mean time of 4.1 weeks for the rise in IOP with maximum IOP elevation 6.6 weeks after $4 \mathrm{mg}$ IVTA. A similar pattern of IOP rise was reported in several other studies (Wingate et al 1999; Jonas et al 2003c; Massin et al 2004; Smithen et al 2004).

Jonas and colleagues (2005) found that young age was the only risk factor for elevated IOP after $20 \mathrm{mg}$ IVTA. A literature search did not reveal similar studies to determine risk factors for elevated IOP after $4 \mathrm{mg}$ IVTA. The purpose of our study is to determine the pattern of increase in the IOP following IVTA, and to identify possible risk factors associated with this increase.

\section{Methods}

This study was a retrospective review of all cases that received IVTA at the American University of Beirut Medical Center and Hotel Dieu de France eye clinics between 2003 and 2005. Only patients with at least 6 months of follow up were included. Those with inadequate follow up or documentation and prior vitrectomy were excluded.

All patients received the treatment knowing that this was an off-label use of triamcinolone acetonide and signed an informed consent. Baseline data included age, gender, phakic status, refractive error, previous ocular diseases including history of glaucoma, and previous medical or surgical interventions. Patients had a complete eye examination that included best corrected visual acuity (BCVA), Goldman applanation tonometery, anterior segment assessment, and dilated fundus examination. Fundus photography, OCT or fluorescein angiography were done as indicated.

All eyes received an intravitreal injection of $4 \mathrm{mg}$ of crystalline triamcinolone acetonide (Kenacort, Myers Squibb, Athens, Greece). This was done as an office procedure. The eye was prepared with 5\% Povidone-iodine solution then lidocaine $1 \%$ was given sub-conjunctivally in the infero-temporal quadrant where the IVTA injection was intended. The IVTA injection was given $3.5 \mathrm{~mm}$ posterior to the limbus through the infero-temporal pars plana using a 27 gauge needle. Paracentesis was done if the optic nerve head was not well perfused 20 minutes after giving the IVTA or if the IOP remained more than $25 \mathrm{mmHg}$. Patients received ciprofloxacin drops (Ciloxan, Alcon, Puurs, Belgium) 3 times per day for 3 days.

The IOP was measured before the injection then at 1, 4, and 12 weeks after the injection, and every 3 months thereafter. A complete eye examination was done at the 4- and 12-week visits and then every 3 months. Topical IOP lowering agents were started if the IOP was more than $25 \mathrm{mmHg}$. Two or more medications were added if necessary to control the IOP. The initial medication used was fixed combination of dorzolamide hydrochloride-timolol maleate (Cosopt, MSD, Haarlem, Netherland). Travoprost (Travatan, Alcon, Fort Worth, USA), brimonidine tartrate (Alphagan, Allergan, Westport, Co. Mayo, Ireland) and acetazolamide (Diamox, Lederle, Maidenhead Berks, UK) were sequentially added in eyes with suboptimal IOP on Cosopt alone. Filtering surgery was done only in refractory cases on 3 or more medications.

Statistical analysis of the collected data was done using SPSS 13.0 software. The Student $t$-test was used to assess sample mean differences of the intraocular pressure. Pearson's correlation test was applied to evaluate associations between different variables and to adjust for inter-eye correlation. The statistical analysis was performed with a $95 \%$ confidence interval.

\section{Results}

One hundred and eighty five patients (81 women and 104 men) were included in the study for a total of 226 eyes. The mean age was 64.2 years (range 22 to 89 years), and the mean refractive error was -0.27 diopters (range -7.25 to +8.00 diopters). The mean follow-up was 8.17 months (range 6 to 24 months). All 185 patients (226 eyes) had 6-month follow-up. However, by 12 and 24 months there were 110 eyes and 40 eyes, respectively.

Indications for IVTA treatment were clinically significant diabetic macular edema (CSME, $\mathrm{n}=146$ eyes), choroidal neovascular membrane associated with age-related macular 
degeneration ( $\mathrm{CNV}$ due to $\mathrm{AMD}, \mathrm{n}=61$ eyes), central retinal vein occlusion (CRVO, $\mathrm{n}=10$ eyes), branch retinal vein occlusion (BRVO, $n=6$ eyes), and uveitis ( $\mathrm{n}=3$ eyes).

In the study group, 46 (20.35\%) eyes had intraocular neovascular diseases related to diabetic retinopathy or central retinal vein occlusion. History of retinal laser surgeries was recorded in 208 eyes (92.03\%). In addition, 109 eyes (48.23\%) had previous cataract surgeries with intraocular lens insertion. The main medical conditions noted among patients were diabetes mellitus ( $\mathrm{n}=127$ patients), and hypertension ( $\mathrm{n}=87$ patients).

The mean number of IVTA injections per eye was 1.31 \pm 0.69 injections, distributed as follows: 173 eyes received 1 injection, 42 eyes received 2 injections, 8 eyes received 3 injections, 2 eyes received 5 injections, and 1 eye received 6 injections.

IOP measurements were obtained at baseline, then at week 1 and month 1 post-injection, followed by evaluations every 3 months. The mean IOP increased after the first IVTA injection from $15.04 \pm 3.18 \mathrm{mmHg}$ at baseline to a mean maximum of $17.20 \pm 5.75 \mathrm{mmHg}(\mathrm{p}<0.0001$, paired t-test $)$ at month 3 of follow-up (Figure 1). A return to mean baseline IOP (15.49 \pm $4.79 \mathrm{mmHg}$ ) was observed at month 12 of follow-up. Table 1 shows the distribution of IOP at different time segments. Seventy four of 226 eyes (33.74\%) or 67 of 185 patients $(36.21 \%)$ had an IOP rise greater than $5 \mathrm{mmHg}$ from baseline.
Of the 226 eyes included in the study, 59 eyes (26.1\%) showed IOP measurements higher than $21 \mathrm{mmHg}$ during follow-up. The mean baseline IOP was $16.57 \pm 3.56 \mathrm{mmHg}$. The difference between the mean baseline and the mean maximal IOP $(22.22 \pm 6.81 \mathrm{mmHg})$, which was noted at 3 months post-injection, was $5.64 \pm 7.69 \mathrm{mmHg}(\mathrm{p}<0.0001)$. A return to a mean normal baseline intraocular pressure $(16.35 \pm 5.43 \mathrm{mmHg})$ was noted at month 12 of follow-up. Similarly, the mean time for an IOP rise greater than $5 \mathrm{mmHg}$ was $3.75 \pm 3.20$ months. This $5 \mathrm{mmHg}$ rise was noted in 45 of the 59 eyes $(76.27 \%)$ and was distributed as follows: 12 of 59 eyes $(20.33 \%)$ at month 1,21 of 59 eyes $(35.59 \%)$ at month 3,10 of 59 eyes (16.94\%) at month 6,1 of 47 eyes $(2.12 \%)$ at month 9 and 1 of 26 eyes (3.84\%) at month 12 of follow-up. Of the 59 eyes that developed IOP greater than $21 \mathrm{mmHg}, 44$ eyes received only 1 injection. Nine of these 44 eyes $(20.45 \%)$ started having IOP greater than $21 \mathrm{mmHg}$ more than 3 months after the injection (Figure 2).

There was no significant difference in IOP change between patients who had baseline IOP $<16 \mathrm{mmHg}$ and those who had baseline IOP $>16 \mathrm{mmHg}$ at 3 months $(\mathrm{p}=0.87)$ and 12 months $(\mathrm{p}=0.44)$ of follow-up.

Eleven $(4.86 \%)$ of the 226 eyes included in the study presented with glaucoma conditions comprising of primary open angle $(n=6)$, neovascular $(n=4)$, and phacolytic $(n=1)$ glaucoma. The rise in IOP did not vary significantly

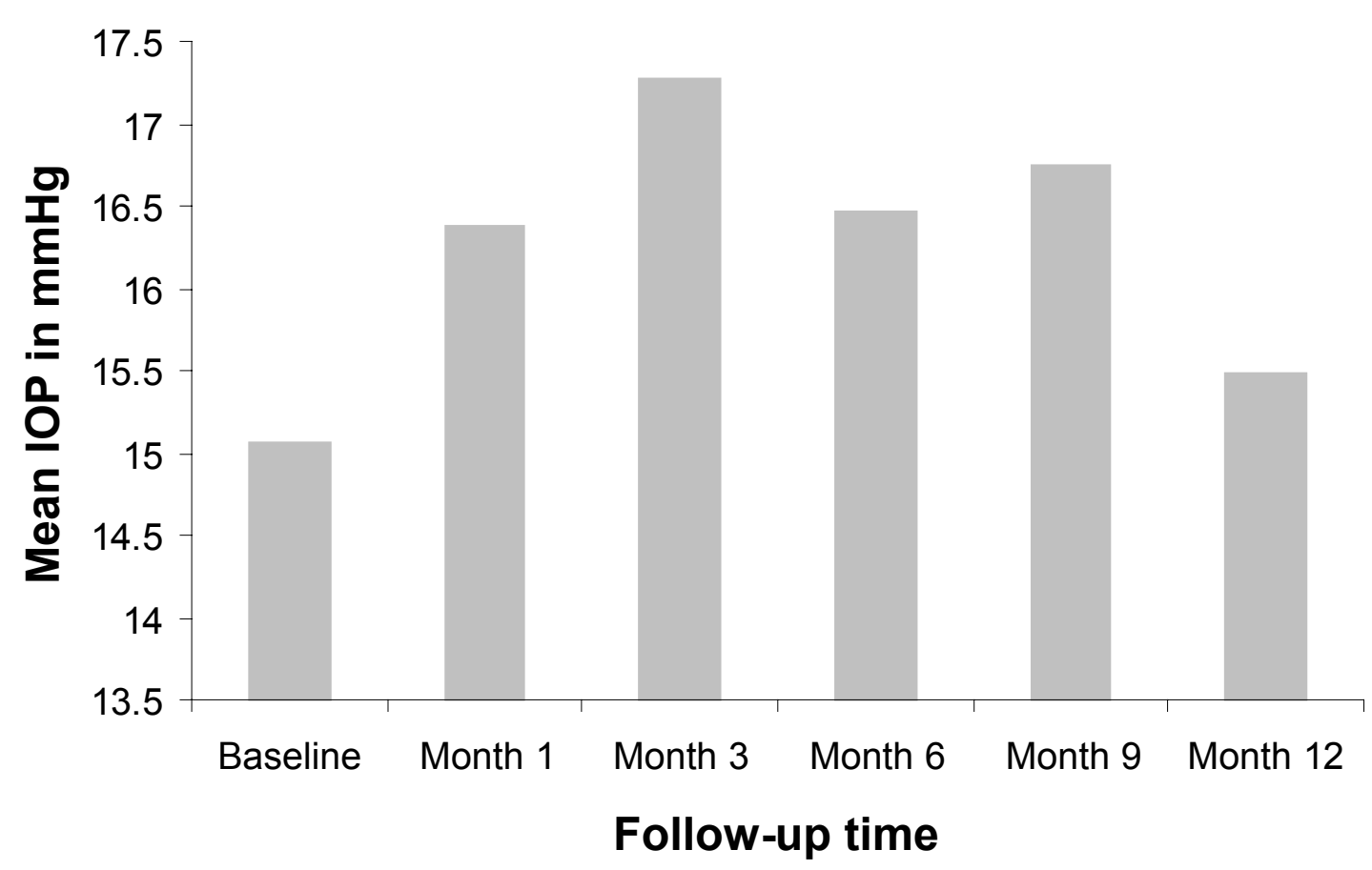

Figure I Bar graph of mean intraocular pressure $(\mathrm{IOP}, \mathrm{mmHg})$ for the entire study group versus follow-up time in months. 
Table I Pattern of elevated intraocular pressure after intravitreal injection of $4 \mathrm{mg}$ triamcinolone acetonide

\begin{tabular}{llllllll}
\hline \multirow{2}{*}{ IOP $(\mathbf{m m H g})$} & \multicolumn{2}{l}{ Percentage of patients over time } \\
\cline { 2 - 8 } & Baseline & I Month & $\mathbf{3}$ Months & $\mathbf{6}$ Months & $\mathbf{9}$ Months & I2 Months & 24 Months \\
\hline$<2$ I & $97.34 \%$ & $89.38 \%$ & $84.95 \%$ & $88.49 \%$ & $86.82 \%$ & $94.54 \%$ & $90 \%$ \\
$>21-<25$ & $2.21 \%$ & $4.42 \%$ & $8.4 \%$ & $7.07 \%$ & $8.38 \%$ & $0.90 \%$ & $5 \%$ \\
$>25-<30$ & $0.44 \%$ & $3.53 \%$ & $2.21 \%$ & $3.53 \%$ & $1.19 \%$ & $1.81 \%$ & $5 \%$ \\
$>30-<35$ & 0 & $1.76 \%$ & $2.21 \%$ & $0.44 \%$ & $2.65 \%$ & $2.72 \%$ & 0 \\
$>35-<40$ & 0 & 0 & $1.76 \%$ & 0 & 0 & 0 & 0 \\
$>40-<45$ & 0 & $0.88 \%$ & 0 & $0.44 \%$ & 0 & 0 & 0 \\
$>45$ & 0 & 0 & $0.44 \%$ & 0 & 0 & 0 & 0 \\
\hline
\end{tabular}

between the glaucoma subgroup $(2.10 \pm 3.90 \mathrm{mmHg})$ and the remaining eyes $(2.16 \pm 6.42 \mathrm{mmHg})$ at month 3 of follow-up $(\mathrm{p}=0.902)$. In addition, there was no statistically significant difference in the change in IOP between phakic and pseudophakic status $(\mathrm{p}=0.421)$.

Intraocular pressure lowering medications were started when the IOP exceeded $25 \mathrm{mmHg}$ in 15 (6.63\%) of the 226 eyes studied. In this subgroup, anti-glaucoma therapy was given to control IOP increase at month 1 after the first IVTA injection in 3 eyes (IOP range: $28-42 \mathrm{mmHg}$ ), at month 3 after the first IVTA injection in 7 eyes (IOP range: $28-38 \mathrm{mmHg}$ ), and at month 6 after a second IVTA injection in 5 eyes (IOP range: $25-40 \mathrm{mmHg}$ ). The intraocular pressure for these 15 eyes had a mean of $17.20 \pm 3.64 \mathrm{mmHg}$ at baseline, reached a maximal mean of $24.28 \pm 9.07 \mathrm{mmHg}(\mathrm{p}=0.016)$ at month 3 of followup, and then returned to mean baseline intraocular pressure of $17.87 \pm 8.77 \mathrm{mmHg}(\mathrm{p}=0.928)$ at month 12 of follow-up.
Statistical analysis was performed to uncover a correlation between the elevation in IOP after IVTA injection and the different parameters included in the study. Using the bivariate logistic analysis (Pearson's correlation), we found no significant associations between the increase in IOP and age, refractive error and the number of IVTA injections. Furthermore, a univariate analysis of variance showed no significant correlations between increase in IOP and gender, glaucoma, phakic status, diabetes, hypertension, and the various underlying ocular diseases (BRVO, CNV due to AMD, CRVO, DME, and uveitis) (Table 2).

\section{Discussion}

Because of its long availability of up to 1.5 years (Jonas 2002a, 2002b, 2004; Beer et al 2003), IVTA has been used increasingly and studied in the treatment of many intraocular conditions, such as proliferative, edematous and neovascular

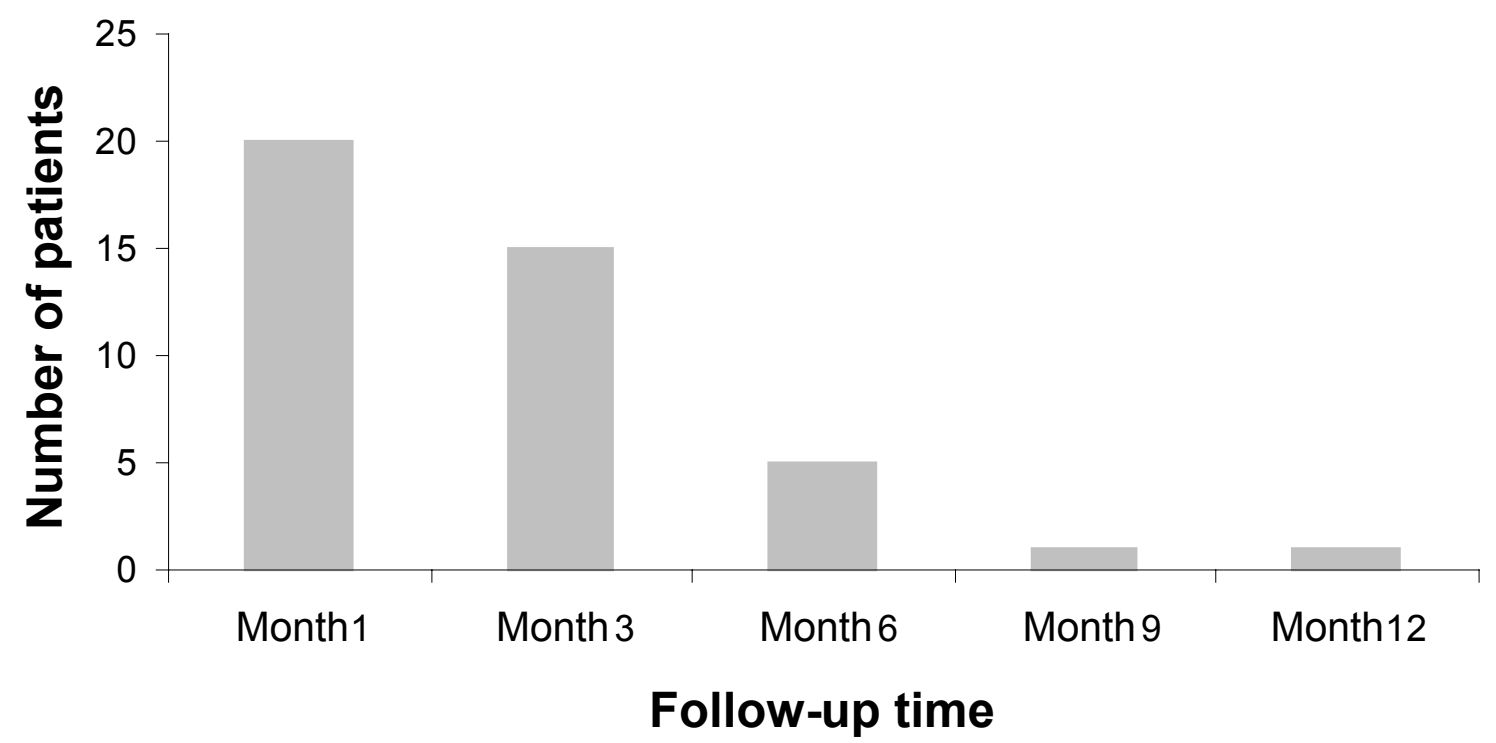

Figure 2 Bar graph representing the number of patients at various follow-ups with elevated intraocular pressure (IOP) after a single IVTA injection. 
Table 2 Correlation between the elevation in IOP after IVTA injection and various variables

\begin{tabular}{lll}
\hline Risk factors & $\begin{array}{l}\text { Correlation } \\
\text { coefficient }(r)\end{array}$ & p value* \\
\hline Age & 0.102 & 0.502 \\
Gender & 0.044 & 0.717 \\
\# of IVTA injections & 0.201 & 0.176 \\
Refractive error & 0.305 & 0.269 \\
Diabetes & 0.17 & 0.199 \\
Hypertension & 0.158 & 0.23 \\
Glaucoma & 0.126 & 0.113 \\
Reason for IVTA injection & & \\
$\quad$ ME & 0.063 & 0.654 \\
CRVO & 0.161 & 0.225 \\
BRVO & 0.134 & 0.963 \\
CNV & 0.109 & 0.4 \\
AMD & 0.151 & 0.254 \\
\hline
\end{tabular}

Note: *Pearson's correlation (SPSS version 13.0, Chicago, IL)

diseases (Wingate and Beaumont 1999; Antcliff et al 2001; Jonas 2001a, 2001b; Degenring and Jonas 2003; Degenring et al 2003; Gillies et al 2003; Jonas et al 2003b; Spaide et al 2003; Massin et al 2004; Smithen et al 2004). In this study up to $26 \%$ of eyes had intraocular pressure rise greater than 21 $\mathrm{mmHg}$ during follow up. The mean IOP peaked at 3 months then returned to normal at month 12 of follow up. Massin and colleagues (2004) found that with 4 mg IVTA injection, IOP exceeded $25 \mathrm{mmHg}$ in $50 \%$ of eyes, and Smithen and colleagues (2004) reported an IOP increase in $40 \%$ of patients who received a single IVTA injection. In a study by Jonas and colleagues (2005), IOP greater than $21 \mathrm{mmHg}$ during a 3 month follow up period was noted in $41 \%$ of eyes given $20 \mathrm{mg}$ IVTA. This higher incidence of elevated IOP in the Jonas study may reflect the higher dose of IVTA.

Our data shows that IOP increased by more than $5 \mathrm{mmHg}$ from baseline in $32.7 \%$ of the eyes or $36.2 \%$ of the patients. Wingate and Beaumont (1999) reported a similar rise in IOP in $30 \%$ of patients who received the same IVTA dose. Bakri and Beer (2003), on the other hand, reported a similar rise in $49 \%$ of eyes receiving $4 \mathrm{mg}$ of IVTA.

Armaly (1963) reported 46\% of glaucoma eyes increased IOP more than $16 \mathrm{mmHg}$ with $0.1 \%$ dexamethasone eye drops. The glaucoma subgroup of patients in this study had a nonsignificant rise in IOP at 6 months post injection with a return to baseline at 1 year post injection. The patients involved were already on antiglaucoma treatment which may explain why they did not have a more pronounced rise in the IOP as may be expected. However, it is note worthy that if there was a larger number of glaucoma patients in the study, the percentage of patients with IOP rise may have been greater.
Despite the latter, the benefit of IVTA injections should be meticulously weighed in glaucoma patients against the risk of significant IOP increase. In our study, glaucoma patients were directly involved in the treatment decision by taking into consideration their potential visual improvement and especially their expectations from the treatment.

Several variables were studied as risk factors for IOP rise. These were namely: age, gender, refractive error, and number of IVTA injections, various reasons for IVTA injection, phakic status, diabetes, hypertension and glaucoma. No significant correlation was noticed with these variables. The absence of correlation with diabetes is in agreement with previous clinical trials where this correlation was investigated (Palmberg 2001).

The major limitations of this study are mainly the retrospective nature of the data and the loss of follow up of many patients over time. Only half the patients (110 of 226 eyes) completed 1 year of follow up, while only 40 patients completed 2 years. Some patients who were lost to follow up may potentially have had an increase in their IOP and thus would have altered the percentage of patients with IOP rise. However, the rise in IOP occurred mainly during the first 6 months post IVTA injection (the first 3 months to be more precise), where all the eyes were still presenting for follow up.

In conclusion, our data shows that IOP elevation can occur in a significant number of eyes receiving $4 \mathrm{mg}$ of IVTA. This phenomenon seems to be transient and a small number of eyes $(6 \%)$ actually required treatment during this period. Eyes that receive IVTA need to be monitored for IOP changes especially during the first 3 months. However, IOP may still rise 6 months and even 12 months after a single injection. This study did not show any risk factors that may predict this IOP rise. Future studies need to look into the relationship between the dose of IVTA and IOP rise. The most clinically effective dose with the least side effects would be recommended.

\section{Disclosure}

Authors have no financial interests in any product or concept discussed in the manuscript. There are no conflicts of interest.

\section{References}

Antcliff RJ, Spalton DJ, Stanford MR. 2001. Intravitreal triamcinolone for uveitic cystoid macular edema: An optical coherence tomography study. Ophthalmology, 108:765-72.

Armaly MF. 1963. Effect of corticosteroids on intraocular pressure and fluid dynamics. Arch Ophthalmol, 70:492-9. 
Bakri SJ, Beer PM. 2003. The effect of intravitreal triamcinolone acetonide on intraocular pressure. Ophthalmic Surg Lasers Imaging, 34:386-90.

Beer PM, Bakri SJ, Singh RJ. 2003. Intraocular concentration and pharmacokinetics of triamcinolone acetonide after a single intravitreal injection. Ophthalmology, 110:681-6.

Benz MS, Murray TG, Dubovy SR. 2003. Endophthalmitis caused by Mycobacterium chelonae abscessus after intravitreal injection of triamcinolone. Arch Ophthalmol, 121:271-3.

Degenring RF, Jonas JB. 2003. Intravitreal injection of triamcinolone acetonide as treatment of chronic uveitis. Br J Ophthalmol, 87:361.

Degenring RF, Kamppeter B, Kreissig I, et al. 2003. Morphological and functional changes after intravitreal triamcinolone acetonide for retinal vein occlusion. Acta Ophthalmol Scand, 81:399-401.

Edelman JL, Lutz D, Castro MR. 2005. Corticosteroids inhibit VEGFinduced vascular leakage in a rabbit model of blood-retinal and bloodaqueous barrier breakdown. Exp Eye Res, 80:249-58.

Gillies MC, Simpson JM, Luo W. 2003. A randomized clinical trial of a single dose of intravitreal triamcinolone acetonide for neovascular age-related macular degeneration: One-year results. Arch Ophthalmol, 121:667-73

Jonas JB, Degenring RF, Kreissig I. 2005. Intraocular pressure elevation after intravitreal triamcinolone acetonide injection. Ophthalmology, 112:593-8.

Jonas JB, Hayler JK, Söfker A, et al. 2001a. Intravitreal injection of crystalline cortisone as adjunctive treatment of proliferative diabetic retinopathy. Am J Ophthalmol, 131:468-71.

Jonas JB, Hayler JK, Söfker A, et al. 2001b. Regression of neovascular iris vessels by intravitreal injection of crystalline cortisone. J Glaucoma, 10:284-7.

Jonas JB, Kreissig I, Degenring RF. 2003a. Endophthalmitis after intravitreal injection of triamcinolone acetonide. Arch Ophthalmol, 121:1663-4.
Jonas JB, Kreissig I, Degenring RF. 2003b. Intravitreal triamcinolone acetonide for pseudophakic cystoid macular edema. Am J Ophthalmol, 136:384-6.

Jonas JB, Kreissig I, Degenring RF. 2003c. Secondary chronic open-angle glaucoma after intravitreal triamcinolone acetonide. Arch Ophthalmol, 121:729-30.

Jonas JB. 2002a. Concentration of intravitreally injected triamcinolone acetonide in aqueous humour. Br J Ophthalmol, 86:1066.

Jonas JB. 2002b. Concentration of intravitreally injected triamcinolone acetonide in intraocular silicone oil. Br J Ophthalmol, 86:1450-1.

Jonas JB. 2004. Intraocular availability of triamcinolone acetonide after intravitreal injection. Am J Ophthalmol, 137:560-2.

Massin P, Audren F, Haouchine B. 2004. Intravitreal triamcinolone acetonide for diabetic diffuse macular edema: Preliminary results of a prospective controlled trial. Ophthalmology, 111:218-24.

Ozkiris A, Erkilic K. 2005. Complications of intravitreal injection of triamcinolone acetonide. Can J Ophthalmol, 40:63-8.

Palmberg P. 2001. Risk factors for glaucoma progression: Where does intraocular pressure fit in? Arch Ophthalmol, 119:897-8.

Smithen LM, Ober MD, Maranan L, et al. 2004. Intravitreal triamcinolone acetonide and intraocular pressure. Am J Ophthalmol, 138:740-3.

Spaide RF, Sorenson J, Maranan L. 2003. Combined photodynamic therapy with verteporfin and intravitreal triamcinolone acetonide for choroidal neovascularization. Ophthalmology, 110:1517-25.

Tamura H, Miyamoto K, Kiryu J, et al. 2005. Intravitreal injection of corticosteroid attenuates leukostasis and vascular leakage in experimental diabetic retina. Invest Ophthalmol Vis Sci, 46:1440-4.

Wingate RJ, Beaumont PE. 1999. Intravitreal triamcinolone and elevated intraocular pressure. Aust N Z J Ophthalmol, 27:431-2. 